\title{
USO DE BIOSSÓLIDOS EM POVOAMENTO DE EUCALIPTO: EFEITO EM ATRIBUTOS QUÍMICOS DO SOLO, NO CRESCIMENTO E NA ABSORÇÃO DE NUTRIE NTE $\mathbf{S}^{(\mathbf{1})}$
}

\author{
L. M. S. VAZ ${ }^{(2)} \&$ J . L. M. GONÇALVES $S^{(3)}$
}

\begin{abstract}
RESUMO
Com o objetivo de avaliar o efeito da aplicação de doses crescentes de biossólido (0, 5, 10, 15, 20 e $40 \mathrm{t} \mathrm{ha}^{-1}$, base seca) em atributos químicos do solo, crescimento e absorção de macro e micronutrientes em um povoamento de Eucal yptus grandis, foi instalado um experimento na Estação Experimental de Itatinga da ESALQ/USP, I tatinga (SP). Alguns tratamentos tiveram suplementação de $\mathrm{K}$ e P e, como referência, em um dos tratamentos foi aplicada adubação mi neral como praticado em empresas florestadoras com alta tecnologia na região.0 solo da área foi caracterizado como Latossolo Vermelho-Amarelo distrófico textura média. Seis meses após a aplicação do biossólido, não foram constatadas alterações do pH e dos teores de $\mathrm{P}, \mathrm{Mg}, \mathrm{Zn}, \mathrm{Cu}$ e B no solo. Foi observada elevação dos teores de $\mathrm{K}$, Ca e $\mathrm{S}$ no solo, bem como redução das concentrações de Al, Fe e Mn, dependendo da dose de biossólido aplicada. Diferentemente, 13 meses após a aplicação do biossólido, percebeu-se a elevação do $\mathrm{pH}$ e dos teores de $\mathrm{P}, \mathrm{Ca}, \mathrm{K}$ e $\mathrm{S}$ somente na camada de $\mathbf{0 - 5} \mathrm{cm}$. Nas duas épocas de amostragem do solo, a elevação das doses de biossólido ocasionou redução dos teores de $\mathrm{MO}$ somente na camada de 0-5 cm. Em compasso com a mineralização da MO no solo, os teores de $\mathrm{N}$ e $\mathrm{S}$ no tecido foliar elevaram-se com o aumento das doses de biossólido em ambas as épocas de amostragem. A disponibilidade de $\mathbf{P}$ assimilável (P-resina) elevou-se, consideravelmente, com o tempo de contato do biossólido com o solo, resultando em maior absorção de $\mathbf{P}$ e crescimento das plantas. A aplicação de fertilizante fosfatado no sulco ou cova de plantio, conjuntamente com o biossólido, mostrou-se necessária para elevar o crescimento inicial das plantas, assegurando atendimento das elevadas demandas iniciais deste nutriente. A suplementação de $\mathrm{K}$ em plantações jovens
\end{abstract}

\footnotetext{
(1) Parte da Tese de Mestrado do primeiro autor, Curso de Pós-Graduação em Ciências Florestais, Escola Superior de Agricultura "Luiz de Queiroz" - ESALQ/USP. Recebido para publicação em setembro de 2000 e aprovado em dezembro de 2001.

(2) Professor Assistente, Departamento de Tecnologia, Universidade Etadual de Feira de Santana - UEFS. Caixa Postal 252-294, CEP 44031-460 Feira de Santana (BA). E-mail: lucianovaz@yahoo.com

(3) Professor do Departamento de Ciências Florestais, Escola Superior de Agricultura "Luiz de Queiroz" - ESALQ/USP. Caixa Postal 9, CEP 13418-900 Piracicaba (SP). E-mail: jlmgonca@carpa.ciagri.usp.br
} 


\begin{abstract}
de eucalipto poderá não ser necessária para doses de biossólido maiores que 10 t ha-1 $^{-1}$ quando as concentrações de $\mathrm{K}$ trocável forem médias. A elevação das doses de biossólido, de 0 a $40 \mathrm{t} \mathrm{ha}^{-1}$, resultou numa resposta quadrática em termos de produção de madeira. A resposta à aplicação de biossólido elevou-se com a idade, refletindo, principalmente, os efeitos benéficos decorrentes da elevação da disponibilidade de nutrientes para as árvores.
\end{abstract}

Termos de indexação: eucalipto, cultivo, adubação orgânica, disponi bilidade de nutrientes.

\title{
SUMMARY: USE OF BIOSOLID IN EUCALYPT STAND: EFFECT ON SOIL CHEMICAL ATTRIBUTES, AND GROWTH AND UPTAKE NUTRIENT BY THE TREES
}

In order to evaluate the effect of increasing biosolid rates $\left(0,5,10,15,20\right.$ and $40 \mathrm{t}^{\mathrm{a}} \mathrm{a}^{-1}$, dry base) on somechemi cal soil attributes, and macroand micronutrient growth and uptake in Eucalyptus grandis stands, an experiment was established at the Experimental Station of I tatinga of ESALQ/ USP, I tatinga (SP). Some treatments had additional application of $K$ and $P$, and, as reference, only mineral fertilization was applied in oneof them as practiced in somehigh technol ogy forest companies in theregion. Thesoil of thearea was characterized as a Red-Y ell ow Latosol dystrophic, medium texture (Oxisol). Six months after thebiosolid application, no pH, P, Mg, Zn, Cu and B changes in the soil wereobserved. Increasing of K, $\mathrm{Ca}$ and $\mathrm{S}$, and reduction of $\mathrm{Al}, \mathrm{Fe}$ and $\mathrm{Mn}$ concentrations were verified. Thirteen months after application, increasing of $\mathrm{pH}$ and $\mathrm{P}$, and $\mathrm{Ca}, \mathrm{K}$ and $\mathrm{S}$ concentrations were verified only in the $0-5 \mathrm{~cm}$ layer. For thetwo samplings, increasing bi osol id rates caused thereduction of organic matter content only at 0-5 $\mathrm{cm}$ soil layer. Accordingly, thel eaf $\mathrm{N}$ and $\mathrm{S}$ concentration increased. AvailableP (resin) increased considerably with biosolid-soil contact time, resulting in a higher uptake of $P$ and plant growth. Theapplication of $P$ fertilizer in the furrow or in the planting hole, simultaneously with bi osolid on soil, was found to benecessary to el evate the initial growth of the plants. No K response was observed. For medium exchangeableK, $\mathrm{K}$ fertilizer appli cation in young eucalypt pl antations may beno necessary for biosol id rates larger than $10 \mathrm{t} \mathrm{ha}^{-1}$. Increasing biosol id rates from 0 to $40 \mathrm{t} \mathrm{ha}^{-1}$ resulted in a quadratic responseof wood production. Theresponseto biosol id application increased with age, mainly due to the beneficial effects of increasing nutrient availability for thetrees.

Index terms: eucalypt, plantation, organic fertilization, nutrient availability.

\section{INTRODUÇÃO}

O potencial de uso do biossólido em plantações florestais, particularmente com espécies de Eucalyptus ePinus, é muito grande. A utilização do biossólido pode resultar em mel horas significativas nas propriedades químicas do solo, influindo, de maneira positiva, na fertilidade. Vários pesquisadores relatam aumentos de $\mathrm{pH}$, matéria orgânica, CTC e teor de macronutrientes, principalmente N, P e Ca, em solos que receberam biossólido (Riekerk, 1981; Berton et al., 1989; Melo et al., 1994; Bevacqua \& Mellano, 1994; Dutch \& Wosltenholme, 1994; Oliveira et al., 1995; Folle et al ., 1995; Ayuso et al ., 1996; Skousen \& Klinger, 1998; Tsutya, 2000; Sui \& Thompson, 2000).
Demodogeral, na Europa, Ásia, América do Norte eAustrália, existem registros de respostas favoráveis de espécies florestais de interesse industrial à aplicação de biossólido. Dentre os efeitos, são relatados: aumentos significativos no diâmetro e altura das árvores, disponibilização de nutrientes (principalmente $\mathrm{N}, \mathrm{P}, \mathrm{Ca}$ e K) e aumento na produtividade do sítio florestal (McNab \& Barry, 1985; Phillips et al., 1986; Weetman et al., 1993; McDonald et al., 1994; Dutch et al., 1994; Henry et al., 1994; Polglase \& Myers, 1996). No Brasil, as pesquisas são muito recentes, ainda em andamento, daí a pouca disponibilidade de dados.

A fertilização de povoamentos florestais com biossólido tem como ponto positivo o fato de que os produtos dessas culturas não são voltados para 
alimentação humana ou animal, diminuindo, portanto, os riscos de contaminação do homem. Contudo, cuidados especiais devem ser tomados em relação à localização, forma e dose de aplicação do lodo, para não ocorrer a contaminação do solo, nascentes, cursos d'água e lençóis freáticos (Gonçalves et al., 2000a).

O objetivo deste trabalho foi avaliar o efeito de doses crescentes de biossólido de estação de tratamento de esgoto em atributos quími cos do solo, crescimento e absorção de macro e micronutrientes em povoamentos de Eucalyptus grandis.

\section{MATERIAL E MÉTODOS}

O estudo foi desenvolvido em condições de campo em área da Estação Experimental de Itatinga, USP/ ESALQ, município de Itatinga (SP) (23000' S, 48응' O e altitude de $750 \mathrm{~m}$ ). O solo da área é um Latossol oVermel ho-Amarel otextura média distrófico. A análise granulométrica na camada de $0-20 \mathrm{~cm}$ apresentou $830 \mathrm{~g} \mathrm{~kg}^{-1}$ de areia, $50 \mathrm{~g} \mathrm{~kg}^{-1}$ de silte e $120 \mathrm{~g} \mathrm{~kg}^{-1}$ de argila. Alguns atributos químicos do solo encontram-se no quadro 1.

A caracterização do biossólido usado no experimento encontra-se no quadro 2 . Trata-se de um resíduo produzido por digestão aeróbica (fase de decantação) e anaeróbica (fase final no digestor). O biossólidoésubmetido a um processo de adensamento e higienização com cloreto férrico $\left(100 \mathrm{~kg}_{\text {de }} \mathrm{FeCl}_{3} \mathrm{t}^{-1}\right.$ de biossólido) e cal extinta ( $250 \mathrm{~kg}$ de cal extinta t-1 de biossólido). O resíduo contém 30 \%, em média, dematéria orgânica, umidade em torno de $60 \%$, pH próximo a 11 e elevados teores de N, P, Ca, Fe, Zn e $\mathrm{S}-\mathrm{SO}_{4}{ }^{2-}$. O biossólido foi aplicado em meados de jul ho de 1998, em faixas de 2 m de largura, na superfície do solo, sem incorporação, mantendo uma distância de 0,5 m de cada lado da linha de plantio do eucali pto.
O resíduo foi aplicado com a sua umidade original (Quadro 2).

A espécie indicadora utilizada foi Eucalyptus grandis Hill Ex Maiden, procedente de Coff's Harbour, Austrália. O plantio com mudas formadas a partir de sementes foi efetuado em março de 1998, noespaçamento $3,0 \times 2,0 \mathrm{~m}$. A relação dos tratamentos experimentais é a que se segue: (1) Testemunha absol uta; (2) Adubação mineral (usada em áreas de produção florestal com al ta tecnologia) - 1,5 t ha-1 de calcário dolomítico (a Ianço em área total), $110 \mathrm{~kg} \mathrm{ha}^{-1}$ de 0-45-0 (sulco de plantio), $150 \mathrm{~kg} \mathrm{ha}^{-1}$ de 10-20-10 (sulco de plantio), $80 \mathrm{~kg} \mathrm{ha}^{-1}$ de $20-0-20$ (45 dias pós-plantio, aplicado em meia-lua ao redor da muda), $180 \mathrm{~kg} \mathrm{ha}^{-1}$ de $16-0-32+0,3 \% \mathrm{~B}+0,5 \%$ deZn (6 a 12 meses pós-plantio aplicado numa faixa contínua na entrelinha de plantio) e $240 \mathrm{~kg} \mathrm{ha}^{-1}$ de 16-0-32 +0,3\% B +0,5 \% de Zn (12 a 18 meses pósplantio, aplicado numa faixa contínua na entrelinha de plantio); (3) 5 t ha-1 de biossólido (base seca), com suplementação de K ; (4) 10 t ha $^{-1}$ de biossólido (base seca), sem suplementação de K; (5) $10 \mathrm{t} \mathrm{ha}^{-1}$ de biossólido (base seca), com suplementação de K; (6)

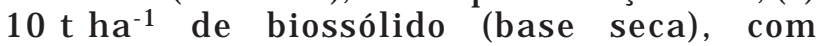
suplementação deK eP (sulco de plantio); (7) 15 t ha${ }^{1}$ de bi ossólido (base seca), com suplementação de K ; (8) $20 \mathrm{t} \mathrm{ha}^{-1}$ de biossólido (base seca), com suplementação de K ; (9) 40 t ha-1 $^{-1}$ de bi ossólido (base seca), com suplementação de K.

O tratamento 2 serve como referência por ser uma das adubações usadas em empresas florestadoras de eucalipto com alta tecnologia na região. Os tratamentos 3, 5, 6, 7 e 9 receberam suplementação de $\mathrm{K}\left(\mathrm{KCl}, 60 \%\right.$ de $\left.\mathrm{K}_{2} \mathrm{O}\right)$, até que a quantidade do $\mathrm{K}$ contido no biossólido somada à do fertilizante potássico ficasse igual à do tratamento 2 . O tratamento 6 recebeu suplementação de P (superfosfato triplo), de modo que a quantidade do $\mathrm{P}$ contido no biossól ido mais a do fertilizante fosfatado ficasse igual à do tratamento $2\left(80 \mathrm{~kg} \mathrm{ha}^{-1} \mathrm{de}_{2} \mathrm{O}_{5}\right)$.

Quadro 1. Atributos químicos ${ }^{(1)}$ do Latossolo Vermelho-Amarelo por ocasião da instalação do experimento

\begin{tabular}{|c|c|c|c|c|c|c|c|c|c|c|c|c|}
\hline Profundidade & pH & MO & $\mathbf{P}$ & $\mathbf{K}$ & $\mathrm{Ca}$ & Mg & $\mathbf{H}+\mathbf{A l}$ & Al & SB & $\mathbf{T}$ & $\mathbf{v}$ & m \\
\hline $\mathrm{cm}$ & & $\mathrm{g} \mathrm{dm}^{-3}$ & $\mathrm{mg} \mathrm{dm}^{-3}$ & \multicolumn{7}{|c|}{$-\mathrm{mmol}_{\mathrm{c}} \mathrm{dm}^{-3}$} & \multicolumn{2}{|c|}{ — $\%$} \\
\hline \multirow[t]{2}{*}{$\begin{array}{c}0-5 \\
5-10 \\
10-20\end{array}$} & $\begin{array}{l}3,6 \\
3,8 \\
3,8\end{array}$ & $\begin{array}{l}56 \\
18 \\
15\end{array}$ & $\begin{array}{l}2 \\
1 \\
1\end{array}$ & $\begin{array}{l}0,9 \\
0,9 \\
0,9\end{array}$ & $\begin{array}{l}3 \\
2 \\
4\end{array}$ & $\begin{array}{l}2 \\
2 \\
1\end{array}$ & $\begin{array}{l}92 \\
53 \\
45\end{array}$ & $\begin{array}{l}19 \\
12 \\
10\end{array}$ & $\begin{array}{l}6 \\
5 \\
5\end{array}$ & $\begin{array}{l}97 \\
59 \\
50\end{array}$ & $\begin{array}{r}5 \\
10 \\
11\end{array}$ & $\begin{array}{l}79 \\
68 \\
65\end{array}$ \\
\hline & & $\mathbf{C u}$ & \multicolumn{2}{|c|}{ Zn } & \multicolumn{2}{|c|}{ Mn } & \multicolumn{2}{|c|}{$\mathbf{F e}$} & \multicolumn{2}{|c|}{$\mathrm{S}-\mathrm{SO}_{4}{ }^{2-}$} & \multicolumn{2}{|c|}{ B } \\
\hline $\begin{array}{c}0-5 \\
5-10 \\
10-20\end{array}$ & & $\begin{array}{l}0,5 \\
0,6 \\
0,7\end{array}$ & $\begin{array}{l}0, \\
0, \\
0,\end{array}$ & & & & & & & & & \\
\hline
\end{tabular}

(1) Segundo métodos apresentados por Raij et al. (1987). 
Quadro 2. Concentração de elementos químicos (formas totais, base seca - 65ㄷ) do biossólido tipo B produzido pela Estação de Tratamento de Esgoto de Barueri (SP)

\begin{tabular}{lrlc}
\hline \multicolumn{1}{c}{ Elemento } & Concentração & Elemento & Concentração \\
\hline $\mathrm{C}\left(\mathrm{g} \mathrm{kg}^{-1}\right)$ & 114,0 & $\mathrm{~S}\left(\mathrm{~g} \mathrm{~kg}^{-1}\right)$ & 6,0 \\
$\mathrm{~N}\left(\mathrm{~g} \mathrm{~kg}^{-1}\right)$ & 26,6 & $\mathrm{Fe}\left(\mathrm{mg} \mathrm{kg}^{-1}\right)$ & 39200 \\
Relação C:N & 4,3 & $\mathrm{Zn}\left(\mathrm{mg} \mathrm{kg}^{-1}\right)$ & 1500 \\
$\mathrm{P}\left(\mathrm{g} \mathrm{kg}^{-1}\right)$ & 9,5 & $\mathrm{Mn}\left(\mathrm{mg} \mathrm{kg}^{-1}\right)$ & 300 \\
$\mathrm{~K}\left(\mathrm{~g} \mathrm{~kg}^{-1}\right)$ & 1,3 & $\mathrm{Cd}\left(\mathrm{mg} \mathrm{kg}^{-1}\right)$ & 21 \\
$\mathrm{Ca}\left(\mathrm{g} \mathrm{kg}^{-1}\right)$ & 95,0 & $\mathrm{~Pb}\left(\mathrm{mg} \mathrm{kg}^{-1}\right)$ & 200 \\
$\mathrm{Mg}\left(\mathrm{g} \mathrm{kg}^{-1}\right)$ & 3,0 & $\mathrm{Umidade}(\%)$ & 60 \\
$\mathrm{Na}\left(\mathrm{g} \mathrm{kg}^{-1}\right)$ & 0,5 & $\mathrm{pH}$ & 10,6 \\
\hline
\end{tabular}

O delineamento experimental utilizado foi o de blocos ao acaso, com nove tratamentos e quatro repetições. Considerando uma área de $6 \mathrm{~m}^{2}$ por planta (espaçamento de plantio igual a 3,0 x 2,0 m), cada parcel a ocupou uma área de $600 \mathrm{~m}^{2}$, totalizando 2,2 ha de área experimental.

Para a amostragem de solo, foram coletadas 10 amostras simples com sonda no sentido diagonal à área útil da parcela (faixa de $2 \mathrm{~m}$ de largura no centro das entrelinhas onde foi aplicado o bi ossólido), obtendo-se uma amostra composta. Os atributos químicos foram determinados para as camadas de 0-5, 5-10 e 10-20 cm de profundidade, avaliando-se as seguintes características: $\mathrm{pH}, \mathrm{MO}, \mathrm{P}, \mathrm{Ca} \mathrm{Mg}, \mathrm{K}, \mathrm{S}$ e Al trocáveis, $\mathrm{H}+\mathrm{Al}$, Soma de Bases (SB), Capacidade de Troca Catiônica (T), Sat. por Bases (V\%) e Sat. por Al (Raij et al., 1987). Foram determinados, também, os teores de $B, C u, F e, M n$ e Zn pelo DTPA (Lindsay \& Norvel, 1978). As amostragens foram feitas aos seis etreze meses após aplicação do biossólido.

Nos $36 \mathrm{~m}^{2}$ centrais de cada parcela, foi derrubada uma árvore, com o diâmetro à al tura do peito (DAP) médio, com vistas em avaliar o volume sólido de madeira, o qual foi estimado pela fórmula de Smallian: $\mathrm{VT}=\left(\mathrm{T}^{2}+\mathrm{B}^{2}\right) \times \mathrm{L} \times \mathrm{C}$, em que: $\mathrm{VT}=$ volumetotal do tronco $\left(\mathrm{m}^{3}\right), \mathrm{L}=$ comprimento de cada segmento de tronco onde se mediu a espessura $(\mathrm{m})$, $\mathrm{T}=$ raio do topo $(\mathrm{cm}) \mathrm{B}=$ raio da base do tronco $(\mathrm{cm})$, e C $=0,0001570796$ (constante).

Nas amostras de fol ha, foram determinados os teores de N, P, K, Ca, Mg eS (Sarruge \& Haag, 1974) e de Fe, Cu, Mn, Zn e B (Malavolta et al., 1997). As amostragens foram realizadas aos doze e vinte e quatro meses do plantio.

Foram determinados a média e o erro-padrão para todos os dados das análises dos atributos químicos do solo e das concentrações foliares de nutrientes. Os dados relativos ao crescimento das árvores foram submetidos a análises de regressão, utilizando o software Sigma Plot 4.0 (J andel Scientific). Como variável dependente, foi usado o volume sólido de madeira e como variável independente as doses crescentes de biossólido.

\section{RESULTADOS E DISCUSSÃO}

\section{E feito do biossólido sobre os atributos químicos do solo e teores foliares de nutrientes}

Seis meses após a aplicação do biossólido, não foram notadas alterações do $\mathrm{pH}$ e dos teores de $\mathrm{P}$, $\mathrm{Mg}, \mathrm{Zn}, \mathrm{Cu}$ e B trocáveis nas camadas analisadas. Foi observada el evação dos teores de K, Ca e S, bem como a tendência ou redução das concentrações de matéria orgânica (MO), Al, Fee Mn (Figuras 1, 2 e 3). Aos 13 meses da aplicação, verificaram-se consideráveis el evações do pH e dos teores de P, Ca, $\mathrm{K}$ eS na camada de $0-5 \mathrm{~cm}$, o que tem estreita rel ação com as características do biossólido (Quadro 2). Os teores de $\mathrm{Ca}$, Zn e Cu foram maiores com doses de 5 a $10 \mathrm{t} \mathrm{ha}^{-1}$, decrescendo a partir da dose de $15 \mathrm{t} \mathrm{ha}^{-1}$, enquanto os teores de B e $\mathrm{Mn}$, para a maioria dos tratamentos, não sofreram alterações (Figuras 1, 2 e3). Abaixo desta camada (dados não apresentados), só os teores de $S$ el evaram-se, aos seis e 13 meses da aplicação do biossólido.

Nas duas épocas de amostragem do solo, com a elevação das doses de bi ossól ido, ocorreu redução dos teores de MO. As maiores reduções foram observadas seis meses pós-aplicação para as mai ores

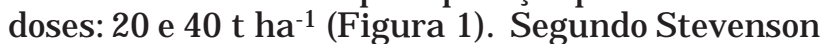
(1986), a adição de material orgânico ao solo pode estimular a decomposição de húmus, graças ao aumento da atividade microbiana. As maiores reduções de MO nos primeiros meses pós-aplicação deveram-se, provavelmente, às maiores disponibilidades de frações de $\mathrm{C}$ facilmente decomponíveis.

Em compasso com a mi neral ização da MO no solo, os teores de $\mathrm{N}$ eS no tecido foliar el evaram-se com o aumento das doses de bi ossóli ido em ambas as épocas de amostragem (Figura 4), possivel mente, graças à mai or absorção deN eS proveniente da mineralização do N-orgâni co do biossól ido e da MO do solo. A maior absorção e assimilação de $\mathrm{N}$ é aceita como uma das principais causas da resposta em crescimento das árvores às doses crescentes de biossólido. No estádio juvenil, até aproximadamente 24 meses, período em que ocorre a expansão da área foliar e sistema radicular, a demanda de $\mathrm{N}$ é muito el evada (Gonçalves et al., 2000b). A adição deste nutriente, principalmente em sol os com baixo teor de matéria orgânica, resulta em acréscimos na taxa de crescimento. Geralmente, este efeito só perdura até o fechamento de copas. A partir daí, a competição por luz e água passa a constituir o fator mais limitante ao crescimento das árvores, e o suprimento de $\mathrm{N}$ via mineralização da matéria orgânica do solo 
e ciclagem de nutrientes atende à demanda das árvores (Barros et al., 1990; Gonçalves et al., 1997, 2000b). Ainda que não resulte em elevações na produtividade de madeira no fim do ciclo, este maior crescimento inicial das árvores, provavelmente causado pelo aumento da disponibilidade de $\mathrm{N}$, é muito desejável, pois reduz os custos de controle de plantas invasoras. (a)

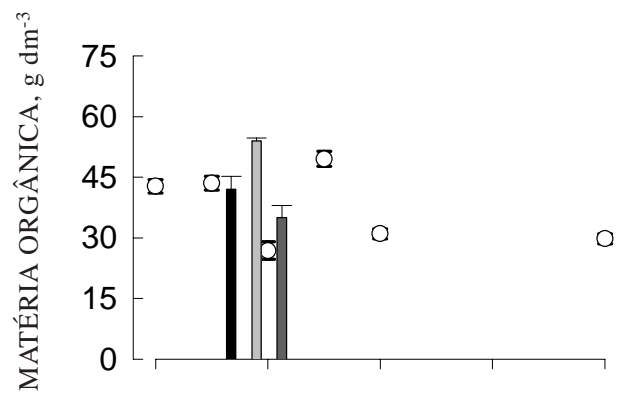

(a)

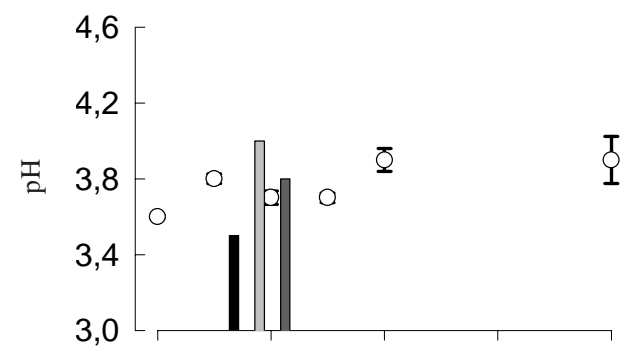

(a)

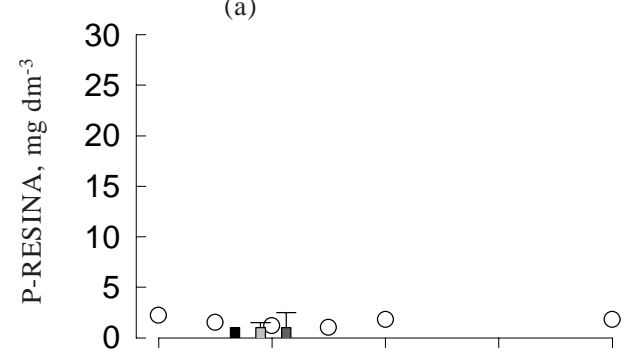

(a)

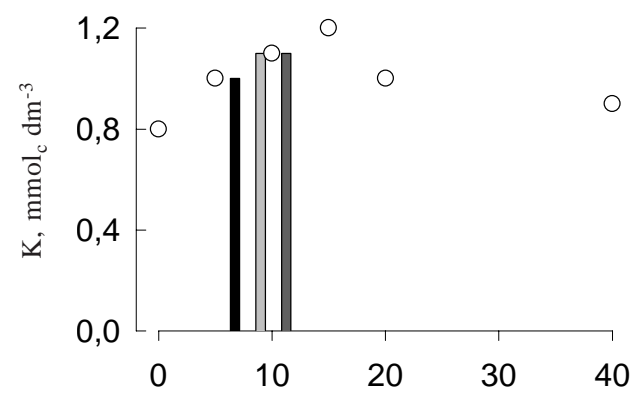

(b)

○ Dose de biossólido Adubação mineral $10 \mathrm{t} \mathrm{ha}^{-1}$ de biossólido 10 t ha $^{-1}$ de biossólido + KP

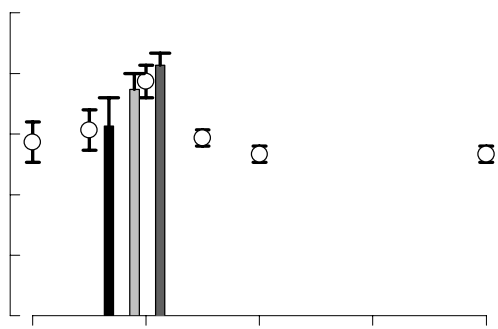

(b)

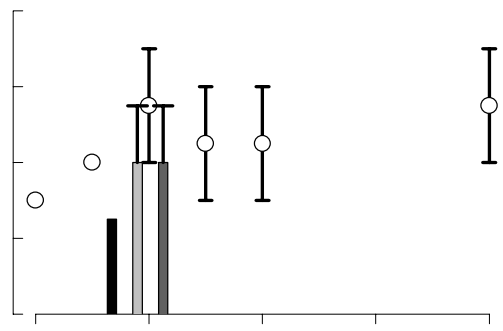

(b)

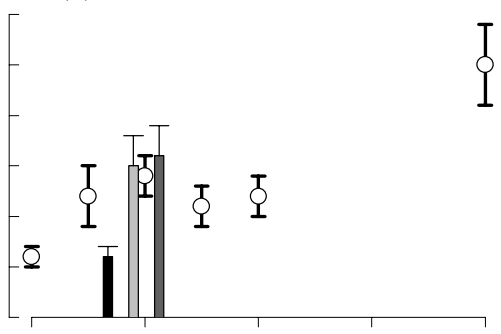

(b)

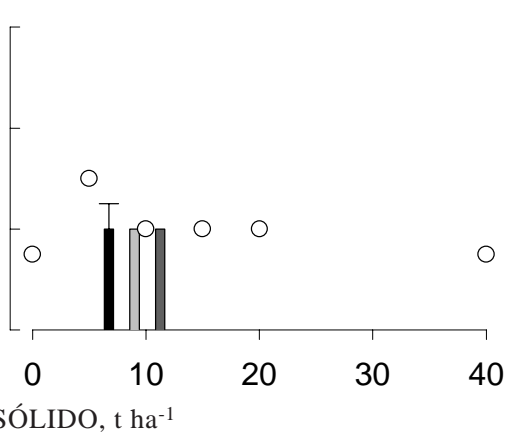

Figura 1. Teores de matéria orgânica, pH e teores de P-resina e de K trocável (média \pm erro-padrão), camada de 0-5 cm, nas entrelinhas do povoamento de Eucalyptus grandis em resposta às doses crescentes de biossólido, com suplementação de $K$ (biossólido $+K \mathrm{Kl}=165 \mathrm{~kg} \mathrm{ha}^{-1} \mathrm{de} \mathrm{K}$ ), às aplicações de $10 \mathrm{t} \mathrm{ha}^{-1}$ de biossólido, sem suplementação de $K$ e com suplementação de $K$ e $P$, e à adubação mineral sem biossólido aos (a) 6 meses e (b) 13 meses da aplicação do biossólido. 


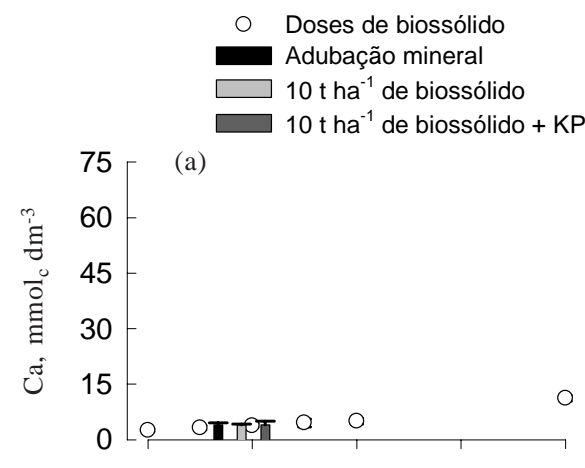

(a)

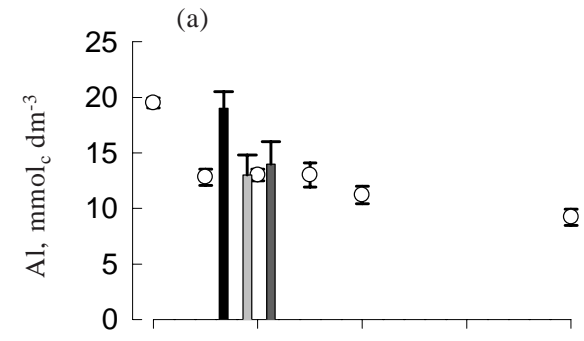

(a)

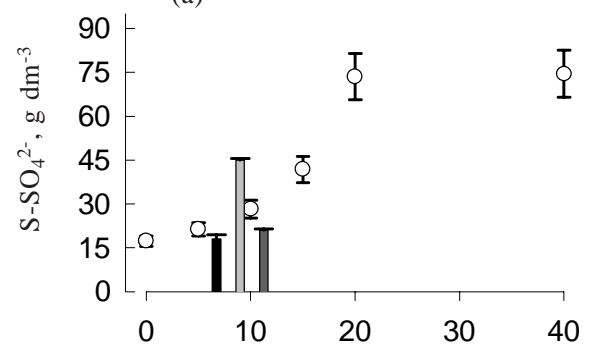

(b)

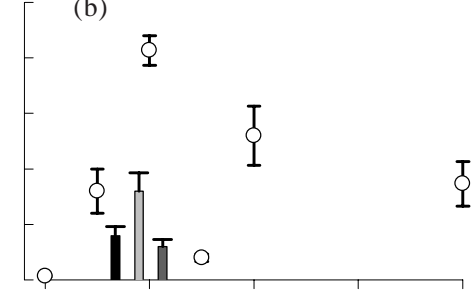

(b)

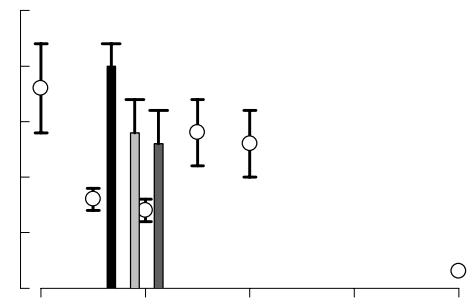

(b)

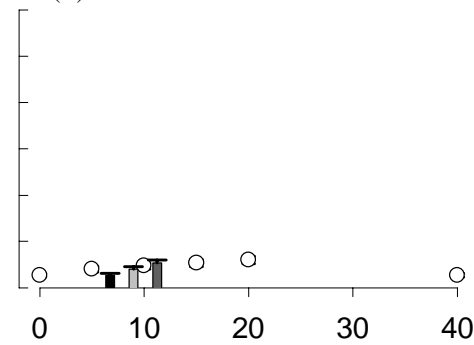

Figura 2. Teores de Ca e Al trocáveis e $\mathrm{S}^{-\mathrm{SO}_{4}}{ }_{4}^{2-}$ (média \pm erro-padrão), camada de 0-5 cm, nas entrelinhas do povoamento de Eucalyptus grandis em resposta às doses crescentes de biossólido, com suplementação de $K$ (biossólido $+K C l=165 \mathrm{~kg} \mathrm{ha}^{-1}$ de $K$ ), às aplicações de $10 \mathrm{t} \mathrm{ha-1}$ de biossólido, sem suplementação de $K$ e com suplementação de $K$ e $P$, e à adubação mineral sem biossólido aos (a) 6 meses e (b) 13 meses da aplicação do biossólido.

Seis meses pós-aplicação do biossólido, não foi constatada alteração dos teores de P-resina na camada de $0-5 \mathrm{~cm}$. Diferentemente, aos 13 meses, foi comprovada considerável elevação dos teores de $\mathrm{P}$ : os teores elevaram-se de $6 \mathrm{mg} \mathrm{dm}^{-3}$, na testemunha, a $25 \mathrm{mg} \mathrm{dm}^{-3}$, no tratamento que recebeu $40 \mathrm{t} \mathrm{ha}^{-1}$ de biossólido (Figura 1). Autores de diversos trabal hos verificaram aumentos noteor deP no solo após a aplicação de biossólido (Phillips et al., 1986; Berton et al., 1989; Dutch \& Wosltenholme, 1994; Oliveira et al., 1995; Folle et al., 1995; Martins et al., 1997), dada a mineralização do P-orgânico contido neste produto (Tsai \& Rosseto, 1992; Tedesco et al., 1999).

Analisando o efeito da disponibilização de P assimilável com o tempo de contato do biossól ido com o solo, verificou-se que todos os tratamentos que receberam esse resíduo, com ou sem suplementação de $P$, não provocaram alterações do teor foliar deste nutriente aos 12 meses de idade, oito meses pósaplicação do biossólido. No tratamento que recebeu apenas fertilização mineral (tratamento 2), oteor de P na planta foi consideravel mente elevado, enquanto o teor de Zn foi reduzido, evidenciando a pronta disponibilidade do P e o antagonismo de absorção desses dois nutrientes (Malavolta et al., 1997) (Figuras 4 e 5).

Por outro lado, aos 24 meses de idade, 20 meses pós-aplicação do biossólido, os teores foliares de $\mathrm{P}$ detodos tratamentos que receberam biossólido, com ou sem suplementação de $\mathrm{P}$, foram maiores do que os obtidos nas plantas do tratamento-testemunha (Figura 4), indicando maior absorção de P. As concentrações de $P$ nestes tratamentos ficaram dentro da faixa considerada adequada para o eucalipto, 0,9 a 1,3 g kg-1 (Gonçalves et al., 1996), 
(a)

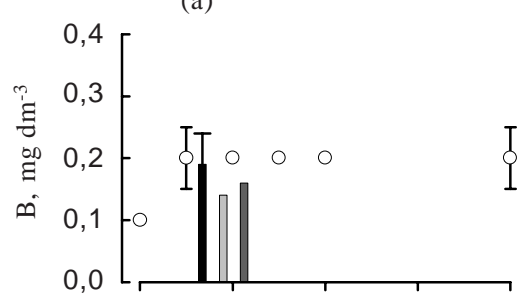

(a)

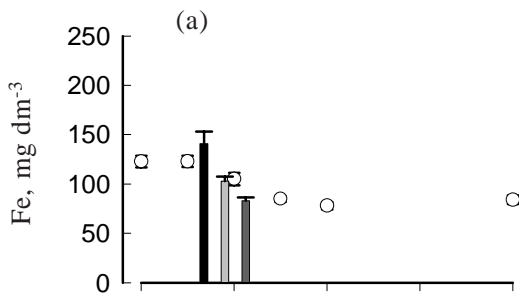

(a)

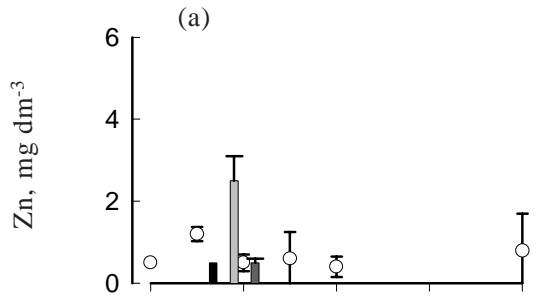

(a)

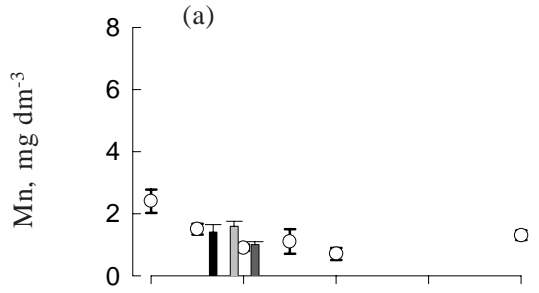

(a)

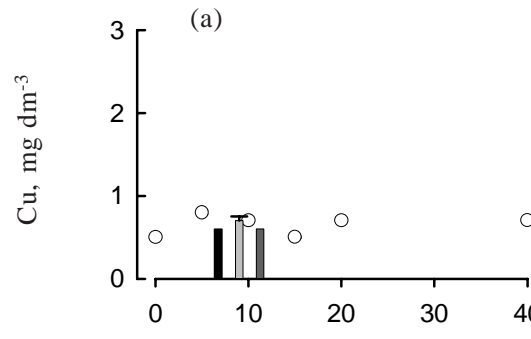

1
- Doses de biossólido

Adubação mineral

(b) $\square 10$ t ha $^{-1}$ de biossólido

$\square 10$ t ha $^{-1}$ de biossólido

0

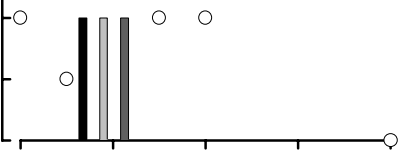

(b)

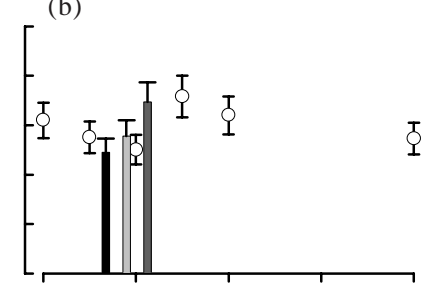

(b)

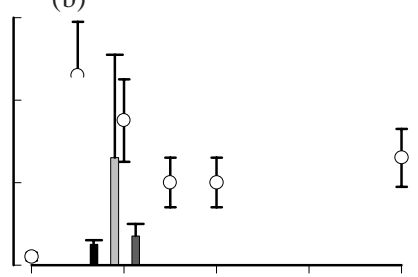

(b)

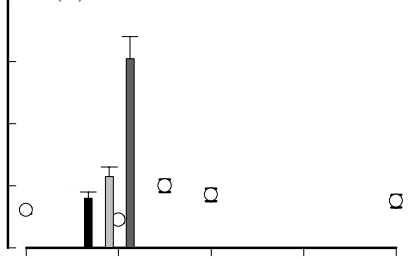

(b)

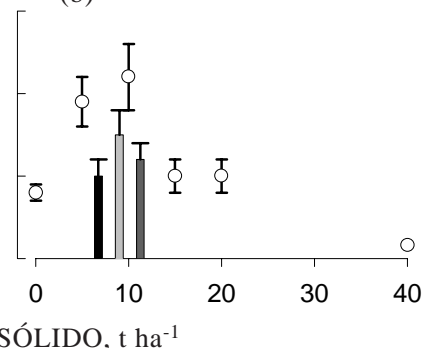

Figura 3. Teores de micronutrientes no solo (média \pm erro-padrão), camada de 0-5 cm, nas entrelinhas do povoamento de E ucalyptus grandi s em resposta às doses crescentes de biossólido, com suplementação de $K$ (biossólido $+K C l=165 \mathrm{~kg} \mathrm{ha}^{-1}$ de $K$ ), às aplicações de 10 t ha ${ }^{-1}$ de biossólido, sem suplementação de $K$ e com suplementação de $K$ e $P$, e à adubação mineral sem biossólido aos (a) 6 meses e (b) 13 meses da aplicação do biossólido.

indicando que, nessa idade, o $P$ não deve estar constituindo um nutriente limitante ao crescimento das plantas.

A aplicação de $10 \mathrm{t} \mathrm{ha}^{-1}$ de biossólido, sem suplementação de K (tratamento 4), elevou o teor desse nutriente de 0,8 (testemunha) para
$1,1 \mathrm{mmol}_{\mathrm{c}} \mathrm{dm}^{-3}$ de solo, seis meses após a aplicação, na camada de $0-5 \mathrm{~cm}$ (Figura 1), atingindo a faixa de teor considerada adequada para o crescimento de eucalipto (Gonçalves et al., 1996). Esses resultados evidenciam que a suplementação de $\mathrm{K}$ em plantações deeucalipto poderá não ser necessária 

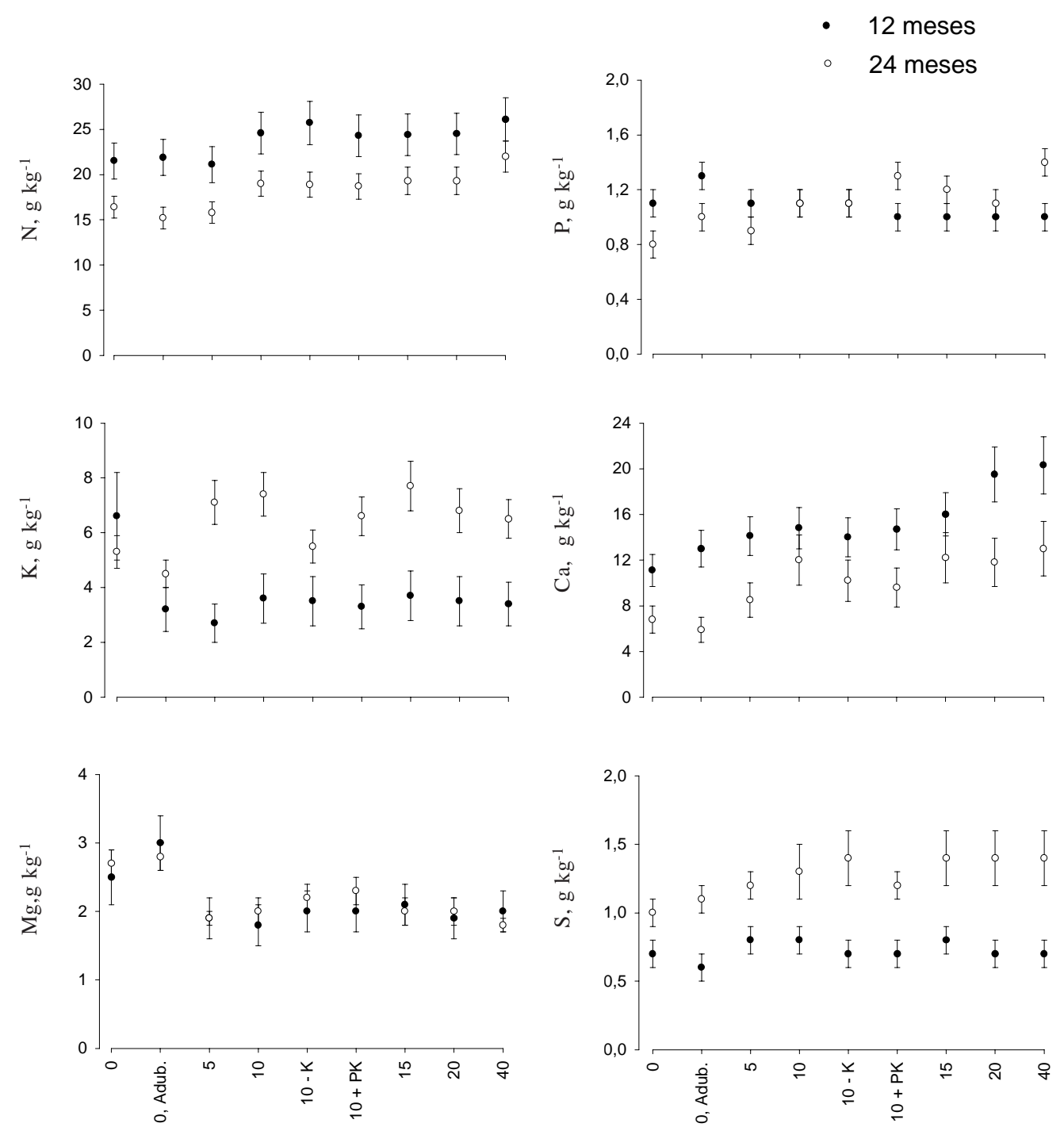

DOSE DE BIOSSÓLIDO, $\mathrm{t} \mathrm{ha}^{-1}$

Figura 4. Concentração foliar de macronutrientes (média terro-padrão) aos 12 e 24 meses de idade das plantas de Eucalyptus grandis, 8 e 20 meses pós-aplicação do biossólido, em resposta às doses crescentes de biossólido, com suplementação de $K$ (biossólido $+K C l=165 \mathrm{~kg} \mathrm{ha}^{-1}$ de $K$ ), às aplicações de $10 \mathrm{t} \mathrm{ha}^{-1}$ de biossólido, sem suplementação de $K$ e com suplementação de $K$ e $P$, e à adubação mineral sem biossólido.

para doses de biossólido maiores que 10 t ha-1, quando as concentrações de $\mathrm{K}$ trocável forem médias $\left(0,08\right.$ a $\left.0,10 \mathrm{mmol}_{\mathrm{c}} \mathrm{dm}^{-3}\right)$. Neste caso, somente o K disponível do biossólido el evaria a fertilidade do solo a níveis suficientes para atender à demanda do eucalipto, que é bem inferior ao da maioria das culturas agrícolas (Raij et al., 1996). Setemeses após, o teor de $\mathrm{K}$ no solo decresceu de 0,8 para $0,3 \mathrm{mmol}_{\mathrm{C}} \mathrm{dm}^{-3}$, na testemunha, e de 1,1 para $0,4 \mathrm{mmol}_{\mathrm{C}} \mathrm{dm}^{-3}$, no tratamento 4 , em decorrência principal mente da absorção e provável lixiviação de K (Figura 1).

As concentrações fol iares deK foram semel hantes em todos os tratamentos que receberam aplicações de biossólido, com ou sem suplementação de K. Por outrolado, o teor deK na testemunha aos 24 meses, o menos produtivo, foi muito superior ao desses tratamentos (Figura 4). U ma das causas prováveis para esta constatação é o "efeito diluição", ou seja, apesar de as plantas apresentarem maior conteúdo de K em sua biomassa foliar, ele dilui-se nesta biomassa, resultando em menor teor deste nutriente.

Aos seis meses da aplicação do biossólido, percebeu-se, apenas no tratamento 9 (40 t ha-1), considerável el evação (0,5 a 0,7 unidade) do pH no sol o em relação aos tratamentos que não receberam aplicação de biossólido, embora não-significativa (Figura 1). Na avaliação posterior (13 meses), não 

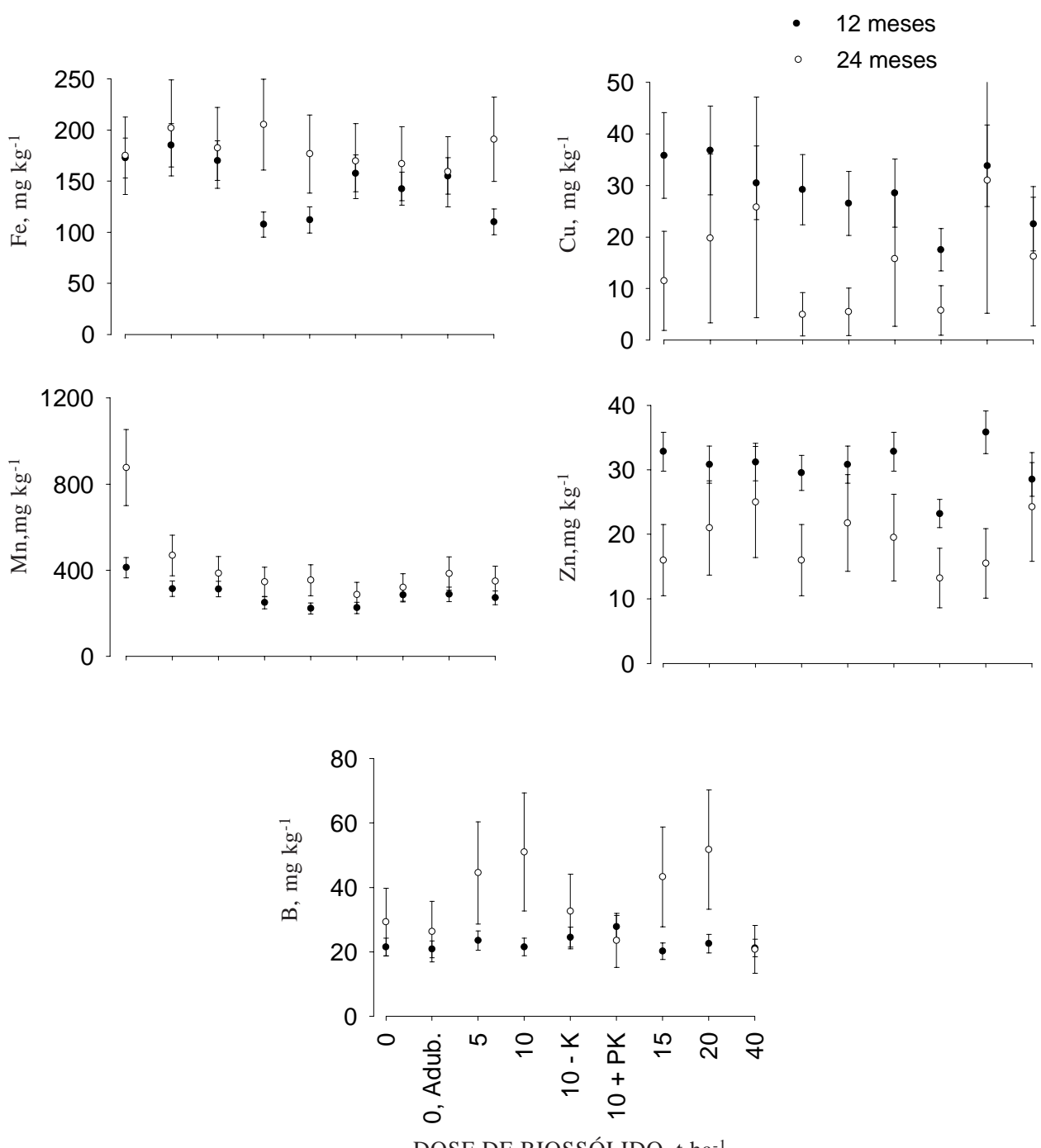

Figura 5. Concentração foliar de micronutrientes (média \pm erro-padrão) aos 12 e 24 meses de idade das plantas de Eucalyptus grandis, 8 e 20 meses pós-aplicação do biossólido, em resposta às doses crescentes de biossólido, com suplementação de $K$ (biossólido $+K \mathrm{Kl}=165 \mathrm{~kg} \mathrm{ha}^{-1}$ de $K$ ), às aplicações de $10 \mathrm{t} \mathrm{ha}^{-1}$ de biossólido, sem suplementação de $K$ e com suplementação de $K$ e $P$, e à adubação mineral sem biossólido.

foram verificadas diferenças entre tratamentos, embora os erros-padrões das médias tenham sido bem maiores; apenas nos tratamentos que receberam biossólido (Figura 1 ).

Alguns autores (Phillips et al., 1986; Berton et al., 1989; Martins et al., 1997) têm relatadoaumentos de $\mathrm{pH}$ no sol o em tratamentos em que o biossólido é incorporado ao solo.

Quando este experimento foi planejado, supondo que o elevado $\mathrm{pH}$ e o teor de $\mathrm{Ca}$ do biossólido pudessem ser prejudiciais ao crescimento inicial das mudas, optou-se por sua aplicação em faixas nas entrelinhas de plantio, sem incorporação ao solo. Diante dos resultados obtidos, supõe-se que a aplicação superficial do biossólido a lanço ou em faixas sobre as linhas de plantio não deva causar injúrias ou desbalanços nutricionais às mudas por causa desse problema.

Houve, 13 meses após a aplicação, nítida el evação do teor deCa no sol o nos tratamentos que receberam biossól ido, maior que no tratamento que só recebeu fertilização mineral (Figura 2). Essas alterações foram pequenas aos seis meses da aplicação. Este aumento do teor de Ca está associado ao seu alto teor no biossólido, $95 \mathrm{~g} \mathrm{~kg}^{-1}$ (Quadro 2), originado no processo de tratamento do resíduo com cal extinta (CaO), para higienização eadensamento do produto. A utilização desse tipo de biossólido como fonte de 
Ca tem sido preconizada por vários autores (Phillips et al., 1986; Berton et al., 1989; Melo \& Marques, 2000; Tsutya, 2000). A el evação do teor de Ca trocável no sol oresultou em mai or absorção deste nutriente, com valores crescentes com o aumento da dose de biossólido (Figura 4).

Considerando tais resultados, deduz-se que, com a aplicação de doses iguais ou superiores a $10 \mathrm{tha-1}$ de biossólido, a suplementação de Ca, via calagem ou outras fontes, é dispensável. I sto tem forte implicação econômica e técnica no manejo de plantações de eucaliptos, porque esta cultura demanda e exporta grandes quantidades de $\mathrm{Ca}$. Além disso, há grandes extensões de solo empobreci dos pela exportação de Ca, após sucessivas colheitas de madeira, sem reposição via calagem (Gonçalves et al., 2000b).

Os decréscimos das disponibilidades de $\mathrm{Cu}$, Zn e Mn no solo (Figura 3) com o aumento da dose de biossólido devem ser, em grande parte, devidos às reações de preci pitação ocasionadas pelas mudanças de $\mathrm{pH}$ e formação de complexos polidentados (quelatos) com os componentes húmi cos do sol o e/ou adsor ção pelas frações minerais ou orgânicas do solo (Tisdaleet al., 1985; Sposito, 1989; Barros et al., 1990; Mello et al., 1994; Miyazawa et al., 1999).

Caso a incorporação do biossól ido fosse realizada, al terações dos atributos relativos à fertilidade do solo seriam mai ores, graças à maior solubilização e reação do biossólido no solo. Contudo, a incorporação de resíduos culturais ou outros insumos não tem sido praticada na maioria dos grandes empreendimentos florestais. Atualmente, tem sido amplamente recomendado o cultivo mínimo do solo, com intuito de prevenir sua degradação física, química e biológica, que não prevê revolvimento do solo (Gonçalves et al., 2000b).

\section{Efeito do biossólido na produção de madeira}

A elevação das doses de biossólido, de 0 a 40 t ha-1, resultou numa resposta quadrática em termos de produtividade de madei ra com casca (Figura 6). Aos 17 meses de idade, 13 meses pós-aplicação do biossólido, o crescimento em vol ume el evou-se de 1,9 para 7,2 $\mathrm{m}^{3} \mathrm{ha}^{-1}$, quando se compara a testemunha com o tratamento que recebeu $40 \mathrm{t}$ ha-1. Este efeito é atribuído, principalmente, ao biossólido. Por exemplo, a aplicação de 10 t ha-1 de biossólido, sem suplementação de K (tratamento 4), resultou num crescimento semel hante àquele obtido com esta mesma dose, com suplementação de K. Como discutido anteriormente, a aplicação desta dose de biossólido, com ou sem suplementação de K, el evou os teores de $\mathrm{K}$ do solo, os quais ficaram dentro da faixa considerada adequada para esta cultura. I sto evidencia que a disponibilidade de K no biossólido pode ser suficiente para o crescimento do eucal ipto, pelo menos na fase juvenil. Aos 24 meses de idade, a aplicação de 10 t ha-1 de biossólido, com ou sem suplementação de K, resultou num crescimento semel hante ao obtido com apenas a aplicação de fertilização mineral.

Comparando o crescimento das árvores nas duas idades (Figura 6), verificou-se que a resposta à aplicação de biossólido eleva-se com a idade, acarretando, principalmente, efeitos benéficos decorrentes da el evação da disponibilidade de nutrientes, oriundos da solubilização e mi neral ização de componentes do resíduo, bem como de um maior volume de sol o expl orado pelas raízes, o que aumenta o acesso a esses nutrientes. Esses efeitos refletiramse numa maior absorção de nutrientes.

O tratamento que recebeu 10 t ha-1 de biossólido mais suplementação de $P$ e K (tratamento 6) resultou em maior resposta, tanto aos 17 como aos 24 meses de idade(Figura 6). O crescimento foi 139 e $32 \%$ superior àquele obtido no tratamento 5 (10 t ha-1 de biossólido mais K, sem suplementação de $\mathrm{P})$, respectivamente, nestas idades.

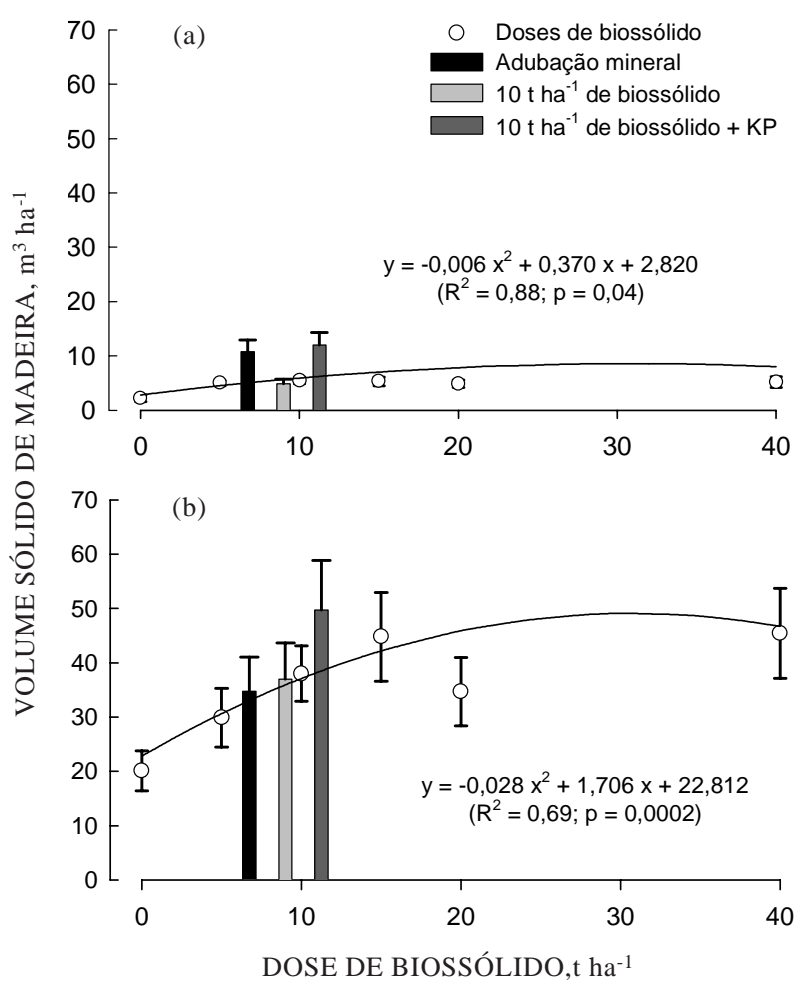

Figura 6. Produtividade de madeira (média \pm desvio-padrão) de Eucalyptus grandis em resposta às doses crescentes de biossólido, com suplementação de $\mathrm{K}$ (biossólido $+\mathrm{KCl}=$ $165 \mathrm{~kg} \mathrm{ha}^{-1}$ de $K$ ), às aplicações de $10 \mathrm{t} \mathrm{ha}^{-1} \mathrm{de}$ biossólido, sem suplementação de $K$ e com suplementação de $K$ e $P$, e à adubação mineral sem biossólido aos (a) 17 meses e (b) 24 meses de idade. 
Comumente, em plantações de eucaliptos, sobretudo no estádio juvenil de crescimento (primeiros dois anos), quando ocorre a expansão da área foliar, a fertilização fosfatada tem sido a mais responsiva eusada. Este efeitoéatribuído às baixas concentrações de $P$ nos solos usados para fins de florestamento, abaixo do nível crítico, como no presente estudo. O nível crítico de $\mathrm{P}$ no sol o para o eucalipto decresce exponencialmente com o tempo de crescimento das árvores, sendo bastante el evado na fase de mudas (Novais et al ., 1982). Por esta razão, a aplicação do fertilizante fosfatado em plantações de eucal ipto tem sido real izada no sulco de plantio, com intuito não só de aumentar a eficiência de aproveitamento do fertilizante, mas também de prover maior disponibilidade de $\mathrm{P}$ junto às raízes das mudas, suprindo suas el evadas demandas iniciais.

Pelo menos duas razões principais podem ser apontadas para a não-resposta ao $P$ contido (9,5 g kg-1 ${ }^{-1}$ Quadro 2) no biossólido: (a) o P está presente em formas não ou lentamente disponíveis e (b) a aplicação do biossólido foi superficial, nas entrelinhas, a 0,5 m das linhas de plantio, portanto, distante das raízes, o que deve ter dificultado sua absorção.

O maior crescimento do eucal ipto no tratamento que recebeu biossólido mais suplementação de $P$ na base (sulco de plantio) indica que esta é uma alternativa potencial para elevar as respostas às apl icações desse resíduo em plantações de eucal ipto. Os custos com a aplicação do biossólido devem ser equi parados ou superados pel os benefícios advindos do aumento de produtividade e com a economia de fertilizantes, sobretudo as fontes de N, Ca, Zn e B. Em outros biossólidos, obtidos a partir de processos que originam produtos com menor $\mathrm{pH}$ e teor de $\mathrm{Fe}$ (sem ou com menor uso de cal e cloreto de Fe), a disponibilidade de $\mathrm{P}$ para as árvores pode ser maior, reduzindo a demanda de suplementação com fertilizantes fosfatados.

O volume sólido de madeira no tratamento que recebeu fertilização mineral (tratamento 2) foi 10 e $30 \%$ inferior ao do tratamento 6 (10 t ha-1 de biossólido $+\mathrm{K}$ e P), aos 17 e 24 meses de idade, respectivamente (Figura 6). Este acréscimo de produtividade no tratamento 6 é atribuído a outras propriedades do biossólido, que não aos efeitos dos nutrientes K e P. É provável que a disponibilização de $\mathrm{N}$ a partir do resíduo e a maior absorção deste nutriente sejam as causas principais desse rendimento (Figura 4).

\section{LITE RATURA CITADA}

AYUSO, M.; PASCUAL, J.A.; GARCIA, C. \& HERNÁNDEZ,T. Evaluation of urban wastes for agricultural use. Soil Sci. Plant Nutr., 42:105-11, 1996.
BARROS, N.F.; NOVAIS, R.F. \& NEVES, J.C.L. Fertilização e correção do solo para o plantio de eucalipto. In: BARROS, N.F. \& NOVAIS, R.F., eds. Relação solo-eucalipto. Viçosa, Folha de Viçosa,1990. p.127-186.

BERTON, R.S.; CAMARGO, O.A. \& VALADARES, J.M.A.S. Absorção de nutrientes pel o milho em resposta à adição de lodo de esgoto a cinco solos paulistas. R. Bras. Ci. Solo, 13:187-192, 1989.

BEVACQUA, R.F. \& MELLANO, V.J . Cumulative effects of sludge compost on crop yields and soil properties. Comm. Soil. Sci. Plant Anal., 25:395-406, 1994.

DUTCH, J. \& WOLSTENHOLME, R. The effects of sewage sludge to a heathland site prior to planting with Sitka spruce. For. Ecol. Manag., 66:151-163, 1994.

FOLLE, F.; SHUFORD, J.W.; TAYLOR, R.W.; MEHADI, A.A.\& TADESSE, W. Effect of sludge treatment, heavy metal, phosphate rate, and $\mathrm{pH}$ on soil phosporus. Comm. Soil. Sci. Plant Anal., 26:1369-1381, 1995.

GONÇALVES, J.L.M.; VAZ, L.M.S.; AMARAL, T.M. \& POGGIANI, F. Aplicabilidade de biossólido em plantações florestais: II Efeito na fertilidade do solo, nutrição e crescimento das árvores. In: BETTIOL, W. \& CAMRGO, O.A., eds. I mpacto ambiental do uso do lodo de esgoto. São Paulo, Empresa Brasileira de Pesquisa Agropecuária, 2000a. p.179-196.

GONÇALVES, J .L.M.; STAPE, J .L.; BENEDETTI, V.; FESSEL, V.A.G. \& GAVA, J.L. Reflexos do cultivo mínimo eintensivo do solo em sua fertilidade e na nutrição das árvores. In: GONÇALVES, J.L.M. \& BENEDETTI, V., eds. Nutrição e fertilização florestal. Piracicaba, Instituto de Pesquisas e Estudos Florestais, 2000b. p.3-57.

GONÇALVES, J.L.M.; BARROS, N.F.; NAMBIAR, E.K.S. \& NOVAIS, R.F. Soil and stand management for shortrotation plantations In: NAMBIAR, S. \& BROWN, A., eds. Management of soil, nutrients and water in tropical plantation forests. Camberra, ACIAR Austrália/CSIRO Austrália/CIFOR Indonésia, 1997. p.379-418.

GONÇALVES, J.L.M.; RAIJ, B. van \& GONÇALVES, J.C. Florestais. In: RAIJ , B. van; CANTARELLA, H.; QUAGGIO, J.A. \& FURLANI,A.M.C., eds. Recomendações de adubação e calagem para o Estado de São Paulo. 2.ed. Campinas, Instituto Agronômico de Campinas \& Fundação IAC, 1996. p.245-259.

HENRY, C.L.; COLE, D.W. \& HARRISON, R.B. Use of municipal sludge to restore and improve site productivity in forestry: the Pack Forest Sludge Research Program. For. Ecol. Manag., 66:137-149, 1994.

LINDSAY, W.L. \& NORVELL, W.A. Development of a DTPA soil test for zinc, iron, manganese and copper. Soil Sci. Soc. Am. J., 42:421-428, 1978.

MALAVOLTA, E.; VITTI, E.C. \& OLIVEIRA, S.A. Avaliação do estado nutricional das plantas (princípios e aplicações). 2.ed. Piracicaba, Associação Brasileira para Pesquisa da Potassa e do Fosfato, 1997. 319p.

MARTINS, L.G.C.; VALLE, C.F. \& BARROS, N.F. Efeitos da aplicação do lodo da indústria de papel e celulose sobre características do solo e sobre a biomassa de raízes de Eucalipto. In:IUFRO CONFERENCE OF SILVICULTURE AND IMPROVEMENT OF Eucalyptus. Salvador, 1997. Anais. Salvador, 1997. p.169-173. 
MCDONALD, M.A.; HAWKINS, B.J .; PRESCOTT, C.E. \& KIMMINS, J.P. Growth and foliar nutrition of western red cedar fertilized with sewage sludge, pulp sludge, fish silage, and wood ash on northern Vancouver Island. Can. J. For. Res., 24:297-301, 1994.

MCNAB, W.H. \& BERRY, C.R. Distribution of aboveground biomass in three pine species planted on a devasted site amended with sewage sludge or inorganic fertlizer. For. Sci., 31:373-382, 1985.

MELO, W.J . \& MARQUES, M.O. Potencial do lodo de esgoto como fonte de nutrientes para as plantas. In: BETTIOL, W. \& CAMARGO, O.A., eds. I mpacto Ambiental do Uso do Lodo de Esgoto. São Paulo, Empresa de Brasileira de Pesquisa Agropecuária, 2000. p.109-141.

MELO, W.J .; MARQUES, M.O.; SANTIAGO, G.; CHELLI, R.A. \& LEITE, S.A.A. Efeito de doses crescentes de lodo de esgoto sobre frações da matéria orgânica e CTC de um latossolo cultivado com cana-de-açúcar. R. Bras. Ci. Solo, 18:449455, 1994.

MIYAZAWA, M.; GIMENEZ, S.M.N.; FERNANDEZ, F.; OLIVEIRA, E.L.D. \& SILVA, S.M.C.P. Efeito do lodo de esgoto nos teores de metais pesados no solo e na planta. In: ANDREOLI, C.V.; LARA, A.I.; FERNANDES, F., eds. Recidagem de Biossólidos: Transformando problemas em soluções . Curitiba, Companhia de Saneamento do Paraná, 1999. p.204-225.

NOVAIS, R.F.; BARROS, N.F.; NEVES, J.C.L.; COUTO, C. Níveis críticos de fósforo para o eucalipto. R. Árvore, 6:29-37, 1982.

OLIVEIRA, F.C.; MARQUES, M.O.; BELLINGIERI, P.A. \& PERECIN, D. Lodo de esgoto como fonte de macronutrientes para a cultura do sorgo granífero. Sci. Agric., 52:360-367, 1995.

PHILLIPS, R.; FISHER, J.T. \& MEXAL, J.G. Fuelwood production utilizing Pinus eldarica and sewage sludge fertilizer. For. Ecol. Manag., 16:95-102, 1986.

POLGLASE, P.J . \& MYERS, B.J . Tree plantations for recyding effluent and biosolids in Australia. In: ELDRIGE, K.G.; CROWE, M.P. \& OLD, K.M., eds. THE J OINT AUSTRALIAN/J APANESE WORKSHOP HELD IN AUSTRALIA, 1., Sydney, 1996. Proceedings. Calligwood: CSIRO, 1996. p.100-109.
RAIJ , B. van; CANTARELLA, H.; QUAGGIO,J .A. \& FURLANI, A.M.C., eds., Recomendações de adubação e calagem para o Estado de São Paulo. 2.ed. Campinas, Instituto Agronômico de Campinas \& Fundação IAC, 1996. 285p.

RAIJ , B. van; QUAGGIO, J.A.; CANTARELLA, H.; FERREIRA, M.E.; LOPES, A.S. \& BATAGLIA, O.C. Análise química do solo para fins de fertilidade. Campinas, Fundação Cargill, 1987. 170p.

RIEKERK, H. Effects of sludge disposal drainage solution of two forests. Soil For. Sci., 27:792-800, 1981.

SARRUGE, J.R. \& HAAG, H.P. Análise química em plantas. Piracicaba, Escola Superior deAgricultura Luiz de Queiroz, 1974. 56p.

SKOUSEN J . \& KLINGER, C. Sewage sludge land application progam in West Virginia. J. Soil Water Conserv., 48:145151, 1998.

SPOSITO, G. Thechemistry of soil. New York, Oxford University Press, 1989. 277p

STEVENSON, F.J . Cycles of soil. Canada, J ohn Wiley $\&$ Sons, 1986. 380p

SUI,Y. \& THOMPSON, M.L. Phosphorus sorption, desorption, and buffering capacity in a biosolids-amended mollisol. Soil Sci. Soc. Am. J., 64:164-169, 2000.

TEDESCO, M.J .; SELBACH,P.A.; GIANELLO,C. \& CAMARGO, F.A.O. Resíduos orgâni cos no solo e os impactos no ambiente. In:SANTOS, G.A. \& CAMARGO, F.A.O., eds. Fundamentos da matéria orgânica no solo: ecossistemas tropicais e subtropicais. Porto Alegre, GENESIS, 1999. p.159-196.

TISDALE, S.L.; NELSON, W.L. \& BEATON, J.D. Soil fertility and fertilizers. New York, Macmillan, 1985. 754p.

TSAI, S.M \& ROSSETO, R. Transformações microbianas do fósforo. In: CARDOSO, E.J.B.N.; TSAI, S.M. \& NEVES, M.C.P., org. Microbiologia do solo. Campinas, Sociedade Brasileira de Ciência do Solo, 1992. p.231-242.

TSUTYA, M.T. Alternativas de disposição final de biossólidos gerados em estações de tratamento de esgotos. In: BETTIOL, W. \& CAMARGO, O.A., eds. I mpacto ambiental do uso do lodo de esgoto. São Paulo, E mpresa Brasileira de Pesquisa Agropecuária, 2000. p.69-105.

WEETMAN, G.F.; MCDONALD, M.A.; PRESCOTT, C.E. \& KIMMINSJ .P. Responses of western hemlock, Pacific silver fir, and western red cedar plantations on northern Vancouver Island to applications of sewage sludge and inorganic fertilizer. Can. J. For. Res., 23:1015-1020, 1993. 